\title{
Immune priming and portal of entry effectors improve response to vibrio infection in a resistant population of the European abalone
}

\author{
Dubief Bruno ${ }^{1,{ }^{*}}$, Nunes Flavia ${ }^{1,2}$, Basuyaux Olivier ${ }^{3}$, Paillard Christine ${ }^{1}$
}

\author{
${ }^{1}$ Laboratoire des Sciences de I'Environment Marin (LEMAR), UMR6539, CNRS/UBO/IRD/Ifremer, \\ Institut Universitaire Européen de la Mer, University of Brest (UBO), Université Européenne de \\ Bretagne (UEB), Place Nicolas Copernic, 29280, Plouzané, France \\ 2 Ifremer Centre de Bretagne, DYNECO, Laboratoire d'Ecologie Benthique Côtière (LEBCO), 29280, \\ Plouzané, France \\ ${ }^{3}$ Synergie Mer et Littoral, Centre Expérimental ZAC de Blainville, 50560, Blainville-sur-mer, France \\ *Corresponding author : Bruno Dubief, email address : $\underline{\text { bruno.dubief@univ-brest.fr }}$
}

\begin{abstract}
:
Since 1997, populations of the European abalone Haliotis tuberculata suffer mass mortalities attributed to the bacterium Vibrio harveyi. These mortalities occur at the spawning season, when the abalone immune system is depressed, and when temperatures exceed $17^{\circ} \mathrm{C}$, leading to favorable conditions for $V$. harveyi proliferation. In order to identify mechanisms of disease resistance, experimental successive infections were carried out on two geographically distinct populations: one that has suffered recurrent mortalities (Saint-Malo) and one that has not been impacted by the disease (Molène). Furthermore, abalone surviving these two successive bacterial challenges and uninfected abalone were used for several post-infection analyses. The Saint-Malo population was found to be resistant to $V$. harveyi infection, with a survival rate of $95 \%$ compared to $51 \%$ for Molène. While in vitro quantification of phagocytosis by flow cytometry showed strong inhibition following the first infection, no inhibition of phagocytosis was observed following the second infection for Saint-Malo, suggesting an immune priming effect. Moreover, assays of phagocytosis of GFP-labelled $V$. harveyi performed two months post-infection show an inhibition of phagocytosis by extracellular products of $V$. harveyi for uninfected abalone, while no effect was observed for previously infected abalone from Saint-Malo, suggesting that the effects of immune priming may last upwards of two months. Detection of $V$. harveyi by qPCR showed that a significantly greater number of abalone from the susceptible population were positive for $V$. harvey $i$ in the gills, indicating that portal of entry effectors may play a role in resistance to the disease. Collectively, these results suggest a potential synergistic effect of gills and haemolymph in the resistance of $H$. tuberculata against $V$. harveyi with an important involvement of the gills, the portal of entry of the bacteria.
\end{abstract}




\section{Highlights}

- Susceptibility to vibriosis differs between abalone from two distinct populations. Immune priming is observed in abalone following a first exposure to $V$. harveyi. The detection of $V$. harveyi is lower in the gills of resistant abalone. The growth rate of $V$. harveyi was lower in the serum of resistant abalone. Both portal of entry and haemolymph effectors may play a role in resistance.

Keywords : Immunity, Haemocyte, Abalone, Disease, Extracellular products, Immune priming, Vibrio harveyi, flow cytometry, Resistance, Phagocytosis, Bacterial growth, qPCR, Gill 


\section{Introduction}

In the natural environment, the interaction between pathogens and their hosts has important

37 evolutionary repercussions, influencing genetic diversity of both hosts and pathogens [1,2]. According to the

38 Red Queen hypothesis, each partner of this couple is in constant antagonist coevolution where pathogens

39 evolve new arms to colonize the host, who in turn develop new features to counteract them. In a stable

40 environment, this arms-race can lead to a balance that prevents one taking advantage over the other.

41 However, global change has the potential to disturb this power relationship. Rapid environmental change can

42 favor pathogens that have shorter generation times than hosts, and thus may adapt to new conditions more

43 quickly whereas the hosts are weakened by them. Among new stressors, global warming is an important factor

44 implicated in the emergence of disease $[3,4]$, with adverse consequences for biodiversity. Many pathogenic

45 bacteria grow preferentially in warm seawater, which can lead to an increase in the prevalence of disease with

46 increasing temperature $[5,6]$. Increasing temperatures can also be detrimental to the immune system of

47 invertebrate hosts thereby facilitating infection by a pathogen. For example, temperature increase leads to a

48 reduction in phagocytosis and phenoloxidase in Haliotis diversicolor infected with Vibrio parahaemolyticus [4].

49 Similarly, temperature increase leads to a reduction in phagocytosis and superoxide dismutase activity, while

50 an increase in total haemocyte count is observed in the hard clam Chamelea gallina [7]. Rising global

51 temperatures can therefore affect both pathogen and host, potentially generating more favorable conditions

52 for disease.

The onset of massive mortalities of the European abalone Haliotis tububerculata is a compelling

54 example of the de-stabilizing effects of environmental change on host-pathogen interactions. Since 1997,

55 recurrent abalone mortality events of 50 to $90 \%$ have been attributed to the bacterium $V$. harveyi [8]. Field

observations and laboratory studies of the disease etiology point to increasing water temperatures as the main

57 cause of the disease. The first known mortalities were reported between Le Trieux and Saint-Malo, where 
summer temperatures are among the highest in northern Brittany, France [9]. Subsequent disease outbreaks were limited to areas where summer temperatures exceeded $17.5^{\circ} \mathrm{C}$ [10]. In support of these field observations, experimental infections showed that $V$. harveyi was only able to cause death by septicemia when water temperatures exceeded $17^{\circ} \mathrm{C}$ during the spawning period of $H$. tuberculata [11]. In addition to temperature, gonadal maturation and spawning of $H$. tuberculata were found to be linked with immune depression characterized by a decrease in phagocytosis and phenoloxydase activity leading to greater susceptibility to the disease [12]. Other external stressors have also been found to lead to immune depression rendering $H$. tuberculata susceptible to disease [13]. However, while the combined effects of higher temperature and gametogenesis are required to trigger an infection in $\mathrm{H}$. tuberculata, below $18^{\circ} \mathrm{C}, \mathrm{V}$. harveyi did not cause mortality in mature abalones [11], showing that temperature remains a key factor for the existence of the disease.

Given the rapid increase of sea surface temperatures [14] and the threat that it represents regarding the evolution of host-pathogen interactions, understanding whether and how marine organisms can defend themselves is of great concern. In the case of $H$. tuberculata infected with $V$. harveyi, the abalone immune system is rapidly affected by the pathogen, as already in the early stages of disease, phagocytosis, the haemocyte density and the production of reactive oxygen species are negatively impacted [15]. Moreover, $V$. harveyi can inhibit phagocytosis by inactivating p38 MAP kinase [16], avoiding the host immune system. While $V$. harveyi appears well-equipped to attack its host, less is known about the potential ability of $H$. tuberculata to defend itself against $V$. harveyi, and whether resistance to the disease exists. A successive infection experiment conducted on farmed abalone that aimed to select resistant individuals and identify potential effectors of resistance found that survivors over-expressed several genes implicated in metabolic regulation [17]. Because coping with stress such as gametogenesis and bacterial infection has an energetic cost, resistance to disease may therefore, be associated with individual or populational differences in metabolism and/or energy allocation strategies.

In the natural environment, recurrent mortality can select for disease resistance. In the black abalone Haliotis cracherodii, resistance against a rickettsial disease was found in the population of San Nicolas Island, which was historically the most impacted by the disease [18]. With respect to $H$. tuberculata, contrasting mortalities have been observed in natural populations in France, raising the question of whether resistant 
populations can be found in areas highly impacted by the disease. Identification of a population tolerant or resistant to the disease could allow resistance factors to be identified.

An additional feature of the invertebrate immune system that can lead to an improved response against a pathogen is immune priming. Immune priming is an adaptive response of the immune system which provides protection in a similar way to the immune memory of vertebrates, but via different biologic mechanisms [19]. Invertebrate immune priming has been observed to be either a specific recognition of a pathogen that then leads to a faster and more intensive immune response at a second exposure [19] or a sustained non-specific immune response following a first infection [20]. In certain species, the enhanced immunity stimulated by priming can be transmitted to the next generation, providing an important advantage to the host in the context of emergent diseases [21]. Immune priming, if present in $\mathrm{H}$. tuberculata, could be an important defense against $V$. harveyi.

The main objectives of this study were (1) to examine the existence of a population of $H$. tuberculata resistant to $V$. harveyi infection; (2) to compare the immune responses of different natural populations during successive exposures to the pathogen, in order to explain differences in tolerance to the disease and (3) to investigate a potential immune priming response of $H$. tuberculata against $V$. harveyi.

\section{Methods}

\subsection{Abalone and bacterial strains}

In order to identify populations with different susceptibilities to the disease, abalones were sampled in an area that has been recurrently impacted by the disease (Saint-Malo) and in a non-impacted area (Molène). Individuals from the two abalone populations were supplied by local commercial fishermen in May 2014: SaintMalo (weight $84.5 \pm 14.3 \mathrm{~g}$; shell length $83.1 \pm 7.6 \mathrm{~mm}$ ) and Molène (weight $82.5 \pm 19.1 \mathrm{~g}$; shell length $84.2 \pm$ $4.4 \mathrm{~mm}$ ). Abalones from the two populations were kept separate, but under the same controlled conditions for approximately five months and fed with Palmaria palmata ad libitum. During this period, the two populations received the same circulating water and the temperature was controlled such that the two populations reached maturity at the same time and as close as possible to the first infection (1300 degree-days). Abalones were transferred to infection tanks two weeks before the start of experimentation (September 2014). The temperature was set to $17^{\circ} \mathrm{C}$ ten days before experimentation and then increased to $18^{\circ} \mathrm{C}$ four days before the 
114

115

infection, in order to prevent uncontrolled bacterial proliferation prior to the experiment. Dead abalones were counted and removed twice daily.

The bacteria used for the challenge is a virulent strain of Vibrio harveyi (ORM4) isolated from diseased abalone in Normandy, France during an episode of massive mortalities in 1999 [8]. Bacteria were grown in Luria-Bertani Agar supplemented with salt (LBS) at a final concentration of $20 \mathrm{~g} . \mathrm{l}^{-1}$ during 72 hours at $18^{\circ} \mathrm{C}$. Prior to use in the experiment, bacteria were washed with filter-sterilized seawater (FSSW) and quantified by optical density measurements at $490 \mathrm{~nm}$. For the post-infection analyses, a modified mother strain of ORM4 was used: a kanamycin resistant strain, tagged with green fluorescent protein (GFP) [22].

\subsection{Bacterial challenge}

Abalones were challenged by two successive infections by immersion separated by a period of four weeks including three weeks of rest. They were placed in $100 \mathrm{~L}$ tanks in a closed system, supplied with seawater maintained at $18^{\circ} \mathrm{C}$ with a summer photoperiod (16h day/8h night) for a number of 22 abalones per tank. For each of the two populations, two conditions were performed in triplicate: a control condition with no bacterial exposure and another condition exposed to $10^{4}$ CFU.ml ${ }^{-1}$ of $V$. harveyi during $24 \mathrm{~h}$. After the $24 \mathrm{~h}$ exposure, water in all the tanks was renewed at $100 \%$, with subsequent water renewals of $50 \%$ taking place each day for the remainder of the infection. A second infection was performed with the surviving abalones 28 days after the first exposure, following the same protocol. During the infection periods, abalones were not fed, but feeding with $P$. palmata resumed during the three-week rest period between the two infections. Dead abalones were counted and removed twice daily. The second infection was followed for one week. After this period, all surviving infected abalones and uninfected (control) abalones were kept for an additional two months at $18^{\circ} \mathrm{C}$ with a summer photoperiod and fed with P. palmata for post-infection analyses.

\subsection{Sampling of abalone hemolymph and tissues}

In order to compare the immune response of the two populations at different time intervals of the disease and between the first and the second infection, live abalone were sampled at 1, 3 and 5 days after the first infection and at 0 (just before exposure), 1 and 3 days after the second infection. Particular attention was given to not sample moribund abalones. For the second infection, sampling at 1 day was only possible for the Saint-Malo population because mortality in the Molène population was too high, and the number of animals 
143

144

145

146

147

148

149

150

151

152

153

154

155

156

157

158

159

160

161

162

163

164

165

166

167

168

169

170

171

remaining was insufficient for 3 sampling points. For each sampling time point, three abalones were taken from each replicate tank. Approximately $5 \mathrm{~mL}$ of hemolymph was collected from each animal with a sterile syringe. $300 \mu \mathrm{l}$ of hemolymph were used immediately for in vitro phagocytosis and total haemocyte count, $500 \mu \mathrm{l}$ was frozen at $-20^{\circ} \mathrm{C}$ for the detection of $V$. harveyi by qPCR. All animals were dissected to collect the gills which were frozen in liquid nitrogen immediately.

\subsection{In vitro phagocytosis index, viability and Total Haemocytes Count (THC)}

Freshly collected hemolymph was used immediately for quantifying phagocytosis, total haemocyte count (THC) and viability by flow cytometry. Three technical replicates were run for each biological replicate.

\subsubsection{Viability index and THC}

$50 \mu \mathrm{l}$ was diluted in $150 \mu \mathrm{l}$ of AASH supplemented with $1 \%$ of Sybr Green fluorescent dye and $1 \%$ of propidium iodide fluorescent dye in a 96-well round-bottom plate. After 20 min incubation at room temperature, the plate was analyzed by flow cytometry. While Sybr Green binds to all nucleic acids present in the sample, and is measured by green fluorescence, propidium iodide can bind only to dead cells that have suffered loss in membrane integrity and is measured by red fluorescence. The THC value was obtained by the number of events showing a green fluorescence divided by the flow rate. The viability index was determined as the percentage of haemocytes which did not show red fluorescence.

\subsubsection{Phagocytosis index using fluorescent beads}

$50 \mu \mathrm{l}$ of hemolymph was diluted in $100 \mu \mathrm{l}$ of FSSW and distributed in a 96-well round-bottom plate. Haemocytes were allowed to adhere for $15 \mathrm{~min}$, followed by the addition of $50 \mu \mathrm{l}$ of $2.00 \mu \mathrm{m}$ fluorescent beads diluted 1:100 in distilled water (Fluoresbrite YG Microspheres, Polysciences) [12]. After $1 \mathrm{~h}$ incubation at $18^{\circ} \mathrm{C}$, the supernatant was removed and $50 \mu \mathrm{l}$ of trypsin $(2.5 \mathrm{mg} \cdot \mathrm{ml}-1)$ in an anti-aggregating solution (AASH: $1.5 \%$ EDTA, $6.25 \mathrm{~g} \mathrm{~L} \mathrm{NaCl}$, in $0.1 \mathrm{M}$ phosphate buffer, $\mathrm{pH}$ 7.4) was added to detach the cells from the bottom of the wells. After $10 \mathrm{~min}$ of shaking at the maximum speed on a Titramax 100 plate shaker (Heidolph), $150 \mu \mathrm{l}$ of AASH was added and the plate was analyzed by flow cytometry with the Guava EasyCyte Plus (Merck Millepore). Beads were identified by their green fluorescence and the phagocytosis index was defined as the percentage of haemocytes phagocyting three or more beads. 
mini kit (QIAgen) according to the manufacturer's protocol. Hemolymph samples were centrifuged at $10000 \mathrm{~g}$ for $10 \mathrm{~min}$. Pellets containing bacteria and haemocytes were digested during $2 \mathrm{~h}$ with ATL buffer supplemented with $20 \mu \mathrm{l}$ proteinase K. Frozen gills were ground with a MM400 mixer mill (RETSCH) and kept frozen using liquid nitrogen. After all subsequent steps of the standard protocol, the columns were eluted twice, first with $150 \mu \mathrm{l}$ of DNase free water, then with $50 \mu \mathrm{l}$. In order to quantify $V$. harveyi in hemolymph, a standard curve was obtained with 10 -fold serial dilution in FSSW of $V$. harveyi bacterial culture, ranging from $10^{8}$ to 0 CFU. In order order to extract DNA under the same conditions as infected gill tissue. A 10-fold serial dilution of bacterial culture from $10^{7}$ to $0 \mathrm{CFU}$ were added to an uninfected abalone gill homogenate of $30 \mathrm{mg} \cdot \mathrm{ml}^{-1}$. Bacteria concentration was estimated using a Malassez counting chamber under light microscopy. chemistry on a LightCycler 480 thermocycler (Roche). Amplification of the $V$. harveyi tox- $R$ gene was done with the following specific primers: ToxR F1 CCA-CTG-CTG-AGA-CAA-AAG-CA and ToxR R1 GTG-ATT-CTG-CAG-GGTTGG-TT. Fluorescent visualization of amplification was done using a tox- $R$ probe dually labeled with the Texas Red 5' reporter dye and the BHQ-2 downstream 3' quencher dye: CAG-CCG-TCG-AAC-AAG-CAC-CG [23]. Each PCR reaction was run in triplicate, containing $5 \mu$ l of DNA, $600 \mathrm{nM}$ of each primer, $200 \mathrm{nM}$ of probes and $7.5 \mu \mathrm{l}$ $10 \mathrm{~min}$, followed by 45 cycles of denaturation at $95^{\circ} \mathrm{C}$ for $10 \mathrm{~s}$, annealing and extension at $58^{\circ} \mathrm{C}$ for $1 \mathrm{~min}$ and 30 $\mathrm{s}$, the fluorescence reading at each cycle at $72^{\circ} \mathrm{C}$ for 1 second. The thresholds were set using LightCycler 480 software V 1.5 (Roche). The primer efficiency was determined by the slope of the standard curves using the equation $E=10^{(-1 / \text { slope })}$.

\subsection{Post-infection analyses}

Abalones surviving the experimental infections (from the Saint-Malo population) and uninfected 
201

202

203

204

205

206

207

208

209

210

211

212

213

214

215

216

217

218

219

220

221

222

223

224

225

226

227

228

229

3D microscopy of intracellular uptake of $V$. harveyi by abalone haemocytes, (2) impact of extracellular products of $V$. harveyi on phagocytosis, and (3) the impact of abalone serum on bacterial growth. To minimize stress each individual was sampled for hemolymph only once.

\subsubsection{D Microscopy of phagocytosis}

Because the methods in flow cytometry used here cannot distinguish whether bacteria are adhered to the surface of a haemocyte or are internalized into the haemocyte, intracellular uptake of $V$. harveyi by abalone haemocytes was confirmed by 3-dimensional fluorescence microscopy for abalone from both Saint-Malo and Molène. Freshly collected hemolymph was diluted ten times in FSSW (100 $\mu \mathrm{l})$ and allowed to adhere for $15 \mathrm{~min}$ on a glass slide. The supernatant was removed and replaced by a GFP $V$. harveyi suspension [22] to obtain a $50: 1$ bacteria to haemocyte ratio. After $1 \mathrm{~h}$ of incubation at $18^{\circ} \mathrm{C}$, the supernatant was removed and glass slides were washed twice with Phosphate Buffered Saline (PBS) pH 7.4 before being fixed for 10 min with $3.7 \%$ formalin in PBS. After two washing steps with PBS, glass slides were covered by $100 \mu$ of a dilution of methanolic stock solution of rhodamine-phalloidin R415 (Invitrogen) with PBS for 20 min, in order to label the actin of cytoskeleton, washed again in PBS, and covered with $100 \mu \mathrm{l}$ of 4', 6-diamidino-2'-phenylindole, dihydrochloride (DAPI) at $0.1 \mu \mathrm{g} \cdot \mathrm{ml}^{-1}$ (Thermo Scientific) for $5 \mathrm{~min}$, to label the nucleus. Finally, the slides were washed with PBS before observation. Slides were observed on an Axio Observer Z1 complemented by the 3D Vivatome module (Carl Zeiss AG). Lasers were used at $\Lambda_{\mathrm{ex}} 494 \mathrm{~nm} \pm 20$ for GFP $\left(\Lambda_{\mathrm{em}} 436 \pm 40\right), \Lambda_{\mathrm{ex}} 406 \mathrm{~nm} \pm 15$ for $\operatorname{DAPI}\left(\Lambda_{\mathrm{em}} 457 \pm 50\right)$, and $\Lambda_{\mathrm{ex}} 575 \mathrm{~nm} \pm 25$ for rhodamine-phalloidin $\left(\Lambda_{\mathrm{em}} 628 \pm 40\right)$. In order to obtain a 3 dimensional image, series of 14 optical cross-sections of $0.8 \mu \mathrm{m}$ were collected and compiled. The images were processed with the AxioVision V 4.8 software (Carl Zeiss AG).

\subsubsection{Impact of extracellular products of $\mathrm{V}$. harveyi on phagocytosis of GFP-labelled bacteria}

Bacterial extracellular products (ECPs) were produced by the cellophane overlay method [24]. Luria Bertani agar plates were covered with sterile cellophane films, and then $2 \mathrm{ml}$ of approximately $10^{9} \mathrm{~V}$. harveyi culture was transferred to the top of the cellophane and incubated at $18^{\circ} \mathrm{C}$ for $72 \mathrm{~h}$. The bacteria and their ECPs were recovered by successive rinsing with $4 \mathrm{ml}$ of FSSW. The ECP/bacteria suspension was centrifuged at 10000 $\mathrm{g}$ for $30 \mathrm{~min}$, and the supernatant containing ECPs was recovered and filtered at $0.2 \mu \mathrm{m}$. ECP concentration was measured by the Bradford method [25], with serum albumin as the standard. Phagocytosis of GFP-labelled 
230

231

232

233

234

235

236

237

238

239

240

241

242

243

244

245

246

247

248

249

250

251

252

253

254

255

256

257

258

$V$. harveyi was measured in the presence of two concentrations of ECPs: 15 and $30 \mu \mathrm{g} \cdot \mathrm{ml}^{-1}$, and a positive control of FSSW containing no ECPs $\left(0 \mu \mathrm{g} \cdot \mathrm{ml}^{-1}\right)$. Flow cytometry was performed on the Guava EasyCyte Plus (Merck Millepore). Phagocytosis values were represented by the mean of green fluorescence following the protocol described in Pichon et al. (2013), using 1 hour incubation.

\subsubsection{Impact of abalone serum on bacteria growth}

The ability of $V$. harveyi to grow in the serum of abalone from Molène and from Saint-Malo was tested using two strains: the virulent ORM4 and the non-virulent strain LMG 7890 [16]. For each abalone population, 1 $\mathrm{ml}$ of hemolymph from 5 individuals was pooled, and then centrifuged at $200 \mathrm{~g}$ for $10 \mathrm{~min}$ in order to recover only the serum, followed by filter-sterilization at $0.2 \mu \mathrm{m}$. Measurements of both ORM4 and LMG 7890 growth were done in 100-well flat-bottom plates with a computer-controlled incubator/reader/shaker, the Bioscreen C MBR. $150 \mu \mathrm{l}$ of serum and $50 \mu \mathrm{l}$ of bacteria suspension in LBS $\left(4 \cdot 10^{4}\right.$ cells. $\left.\mathrm{ml}^{-1}\right)$ were pipetted into each well. In order to have a stable control against which to compare bacterial growth in the serum of abalone from Molène and Saint-Malo, a positive control of growth was performed for both strains by adding $50 \mu$ l of bacteria suspension with $150 \mu$ l of LBS. A negative control was performed by adding $50 \mu$ of sterile LBS with $150 \mu$ l of serum. Each condition was performed in triplicate. The plate was incubated at $18^{\circ} \mathrm{C}$ for 42 hours and the absorbance at $492 \mathrm{~nm}$ was measured at intervals of $30 \mathrm{~min}$. The bacterial concentration was calculated with the following formula: $6 \cdot 10^{9} \times O D+2 \cdot 10^{8}$ [22]. The maximum growth rate for each condition was obtained by calculating the slope of the bacterial exponential growth phase from a plot of the natural logarithm of bacterial abundance versus incubation time.

\subsection{Statistical analysis}

The survival rate of infected and uninfected abalone from Saint-Malo and Molène was computed with a Kaplan-Meier estimate followed by a log-rank test in the R "survival" package[27]. Phagocytosis and THC data were fitted on a linear mixed effects model with the factor tanks as random effect, followed by a pairwise comparison of the least-squares means between uninfected and infected treatments. The effects of ECP on phagocytosis for each population were estimated by a 2-way nested ANOVA. As the hemolymph of each individual was used to quantify phagocytosis under three concentrations of ECPs (conditions 0,15 and 30 $\mu \mathrm{g} \cdot \mathrm{ml}^{-1}$ ), individuals were considered as repeated factors. Then pairwise comparisons of the least-squares 

the link between the phagocytosis index and the probability of abalone to be positive for $V$. harveyi; and to evaluate if there were differences in the probability of being positive for $V$. harveyi for abalone originating from Saint-Malo or Molène. In all tests, at the significance threshold was set to $\alpha=\mathrm{P}<0.05$. All statistical analyses were performed using the software R (version 3.2.3)[28].

264

\section{Results}

266

\subsection{Differential survival of abalone following V. harveyi infection in Saint-Malo and Molène}

$V$. harveyi between the two populations. Indeed, during the first infection, the population of Molène suffered great mortalities whereas the population of Saint-Malo exhibited very little mortality. After the last observed mortality (24 days after the first exposure), the survival rate was 0.512 for Molène and 0.953 for Saint-Malo (Fig. 1). Survival for the Saint-Malo population was not significantly different from the uninfected controls

$273(P=0.765)$. The log-rank test showed a significant difference in survival between the two infected populations $274(P<0.001)$. Survival was quantified only until 7 days after the second exposure, and by this time point no additional mortality was observed. 


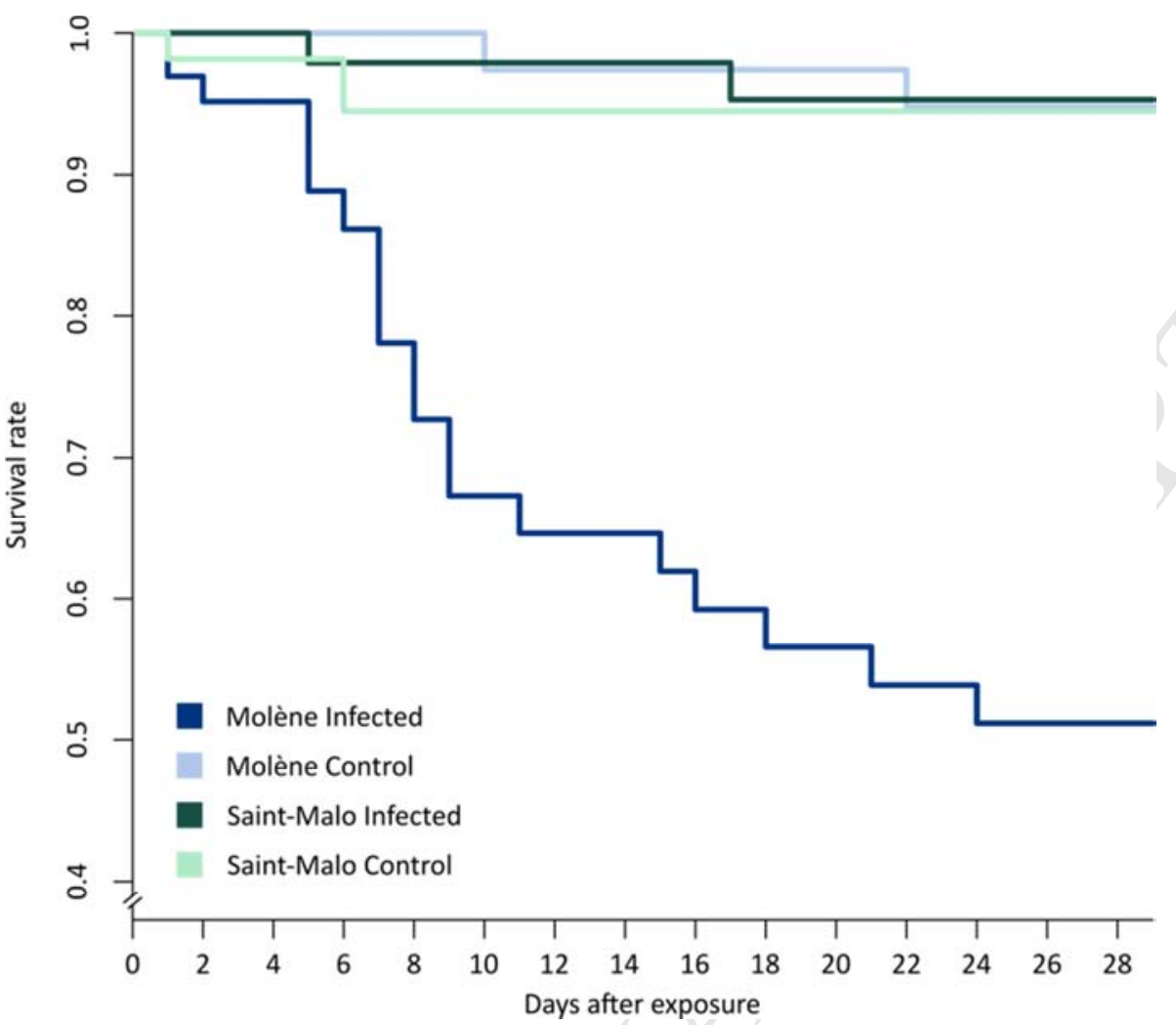

Fig. 1 : Kaplan-Meier survival rate following the first exposure of the two populations to $10^{4}$ bacteria/mL during 24 hours at $18^{\circ} \mathrm{C}$

277

278

279

280

281

282

283

284

\subsection{THC and Viability during the successive infections}

Total haemocyte count (THC) and haemocyte viability were measured for individuals from Saint-Malo and Molène. Whereas no significant differences in THC were observed in abalones from Saint-Malo across all time points, abalones from Molène exhibited a significant increase in THC after 24h of exposure (Fig. 2). A slight decrease of THC was observed during the second infection for abalones from Saint-Malo but was not significant $(P=0.0947)$. No change was detected in the viability of haemocytes during the successive infections in both populations. The mean of haemocyte viability was $98.44 \pm 0.09 \%$ across all individuals measured. 


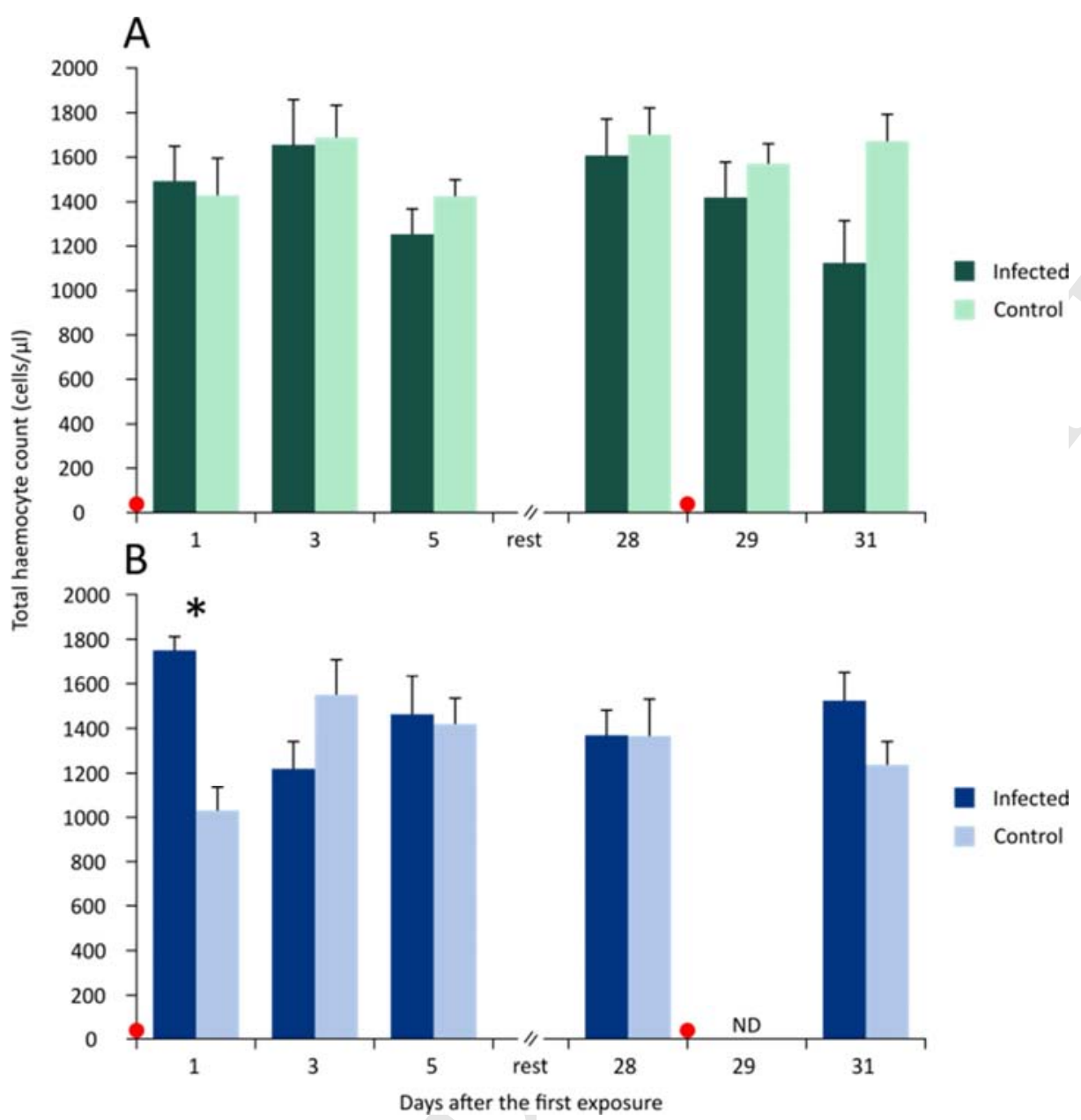

Fig. 2: Total haemocytes count (THC) during the two exposures of (A) Saint-Malo and (B) Molène. Red dots indicate the exposures. ND indicates that no data is available.* indicates values that are significantly different from the control for a pairwise comparison of the least-squares means $(p<0.05)$.

A significant decrease in the phagocytosis index was observed 1 day after the first exposure to $V$. harveyi, of $36 \%$ for Molène and $40 \%$ for Saint-Malo, relative to the uninfected abalone (Fig. 3). By 2 days, the phagocytosis index of infected abalones recovered to the level of the uninfected controls and remained at the level of the controls until 5 days post-infection. Just prior to the second exposure, no significant difference in the phagocytosis index was observed between infected abalone and uninfected controls for the two populations. During the second infection, no reduction in phagocytosis was observed in the infected abalones from Saint-Malo and the level of phagocytosis was not significantly different than that of uninfected controls until the end of the experiment. In contrast, abalone from Molène showed a significant decrease in 


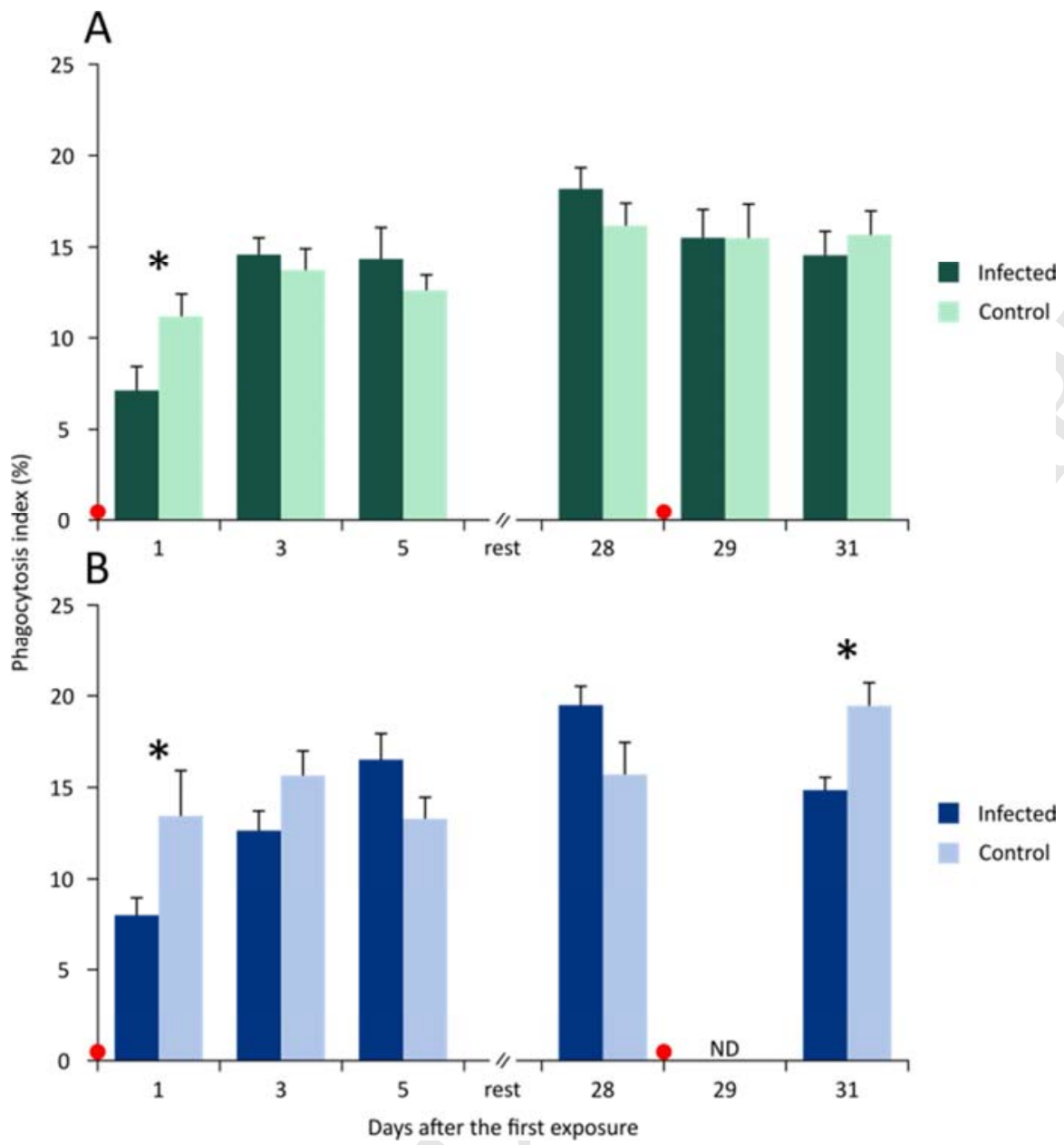

Fig. 3: Phagocytosis index based on micro-beads engulfment (percentage of haemocytes containing three or more fluorescent beads relative to total haemocytes) during two successive infections of abalone from (A) Saint-Malo and (B) Molène. Red dots indicate the timing of bacterial exposure. ND indicates that no data is available.* indicates values that are significantly different from the control for a pairwise comparison of the least-squares means $(p<0.05)$.

The sensitivity threshold of qPCR was estimated to be $7.5 \cdot 10^{2}$ bacteria/ml of hemolymph and $2.5 \cdot 10^{2}$ bacteria/30 mg of tissue for gills. V. harveyi was detected in the gills of 20 individuals and in the hemolymph of 7 individuals (fig. 4). The concentration of bacteria was in the range of $5.51 \cdot 10^{2} \pm 57$ bacteria/30 $\mathrm{mg}$ of gills and $6.4 \cdot 10^{3} \pm 2.02 \cdot 10^{3}$ bacteria/ml of hemolymph. One individual showed $1.8 \cdot 10^{4}$ bacteria/ml of hemolymph, which explains the high standard deviation for this compartment (the average without this outlier individual was $4.52 \cdot 10^{3} \pm 7.23 \cdot 10^{2}$ bacteria/ml of hemolymph). As the concentration of $V$. harveyi was near the detection threshold for most samples from which $V$. harveyi was detected, the detection results were treated as positive 
Table 1: Logistic regression examining the effect of the population(pop), the phagocytosis index (phago) and the total haemocytes count (THC), on the proportion of abalones positive to $\mathrm{V}$. harveyi on the gills. $(*)$ For THC, the estimate and odds ratio are calculated for an increase of 500 cells $/ \mu \mathrm{L}$.

\section{Coefficients:}

\begin{tabular}{|c|c|c|c|c|c|}
\hline & Estimate & odds ratio & std. Error & $z$ value & $\operatorname{Pr}(>|z|)$ \\
\hline (Intercept) & $-5,02786$ & 0,00655282 & 2.19997 & -2.285 & 0.02229 \\
\hline pop & 2,55707 & 12,8979708 & 0.80107 & 3.192 & 0.00141 \\
\hline phago & $-0,17121$ & 0,8426446 & 0.07558 & -2.265 & 0.02350 \\
\hline $\mathrm{THC}^{(*)}$ & 1,30651 & 3,69326171 & 0.50927 & 2.565 & 0.01030 \\
\hline
\end{tabular}




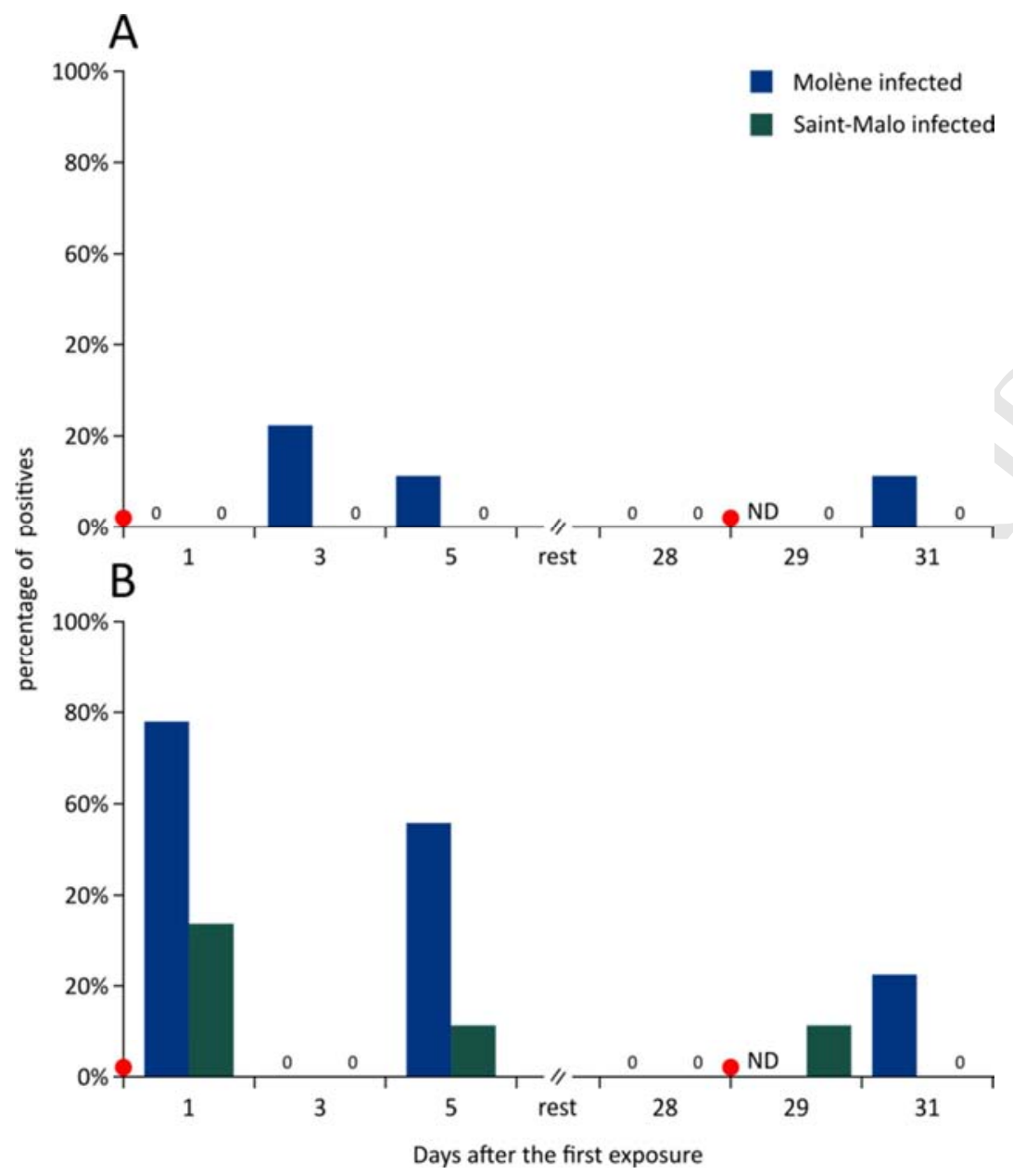

Fig. 4: Percentage of positive individuals for V.harveyi $(n=9)$ in $(A)$ haemolymph and (B) gills obtained by qPCR using specific primers and a TaqMan probe. The number 0 indicates that no individuals were found as positive at a given population and time point. Red dots indicate the timing of bacterial exposure. ND indicates that no data is available.

\subsection{Post-infection analyses:}

\subsubsection{Fluorescence microscopy of phagocytosis}

In order to validate that $V$. harveyi is internalized rather than adhered externally to abalone 
and $\mathrm{x}$-axes, confirm that bacteria are inside haemocyte cells and not merely at the surface. Similar images were obtained using haemocytes from individuals from both Saint-Malo and Molène.

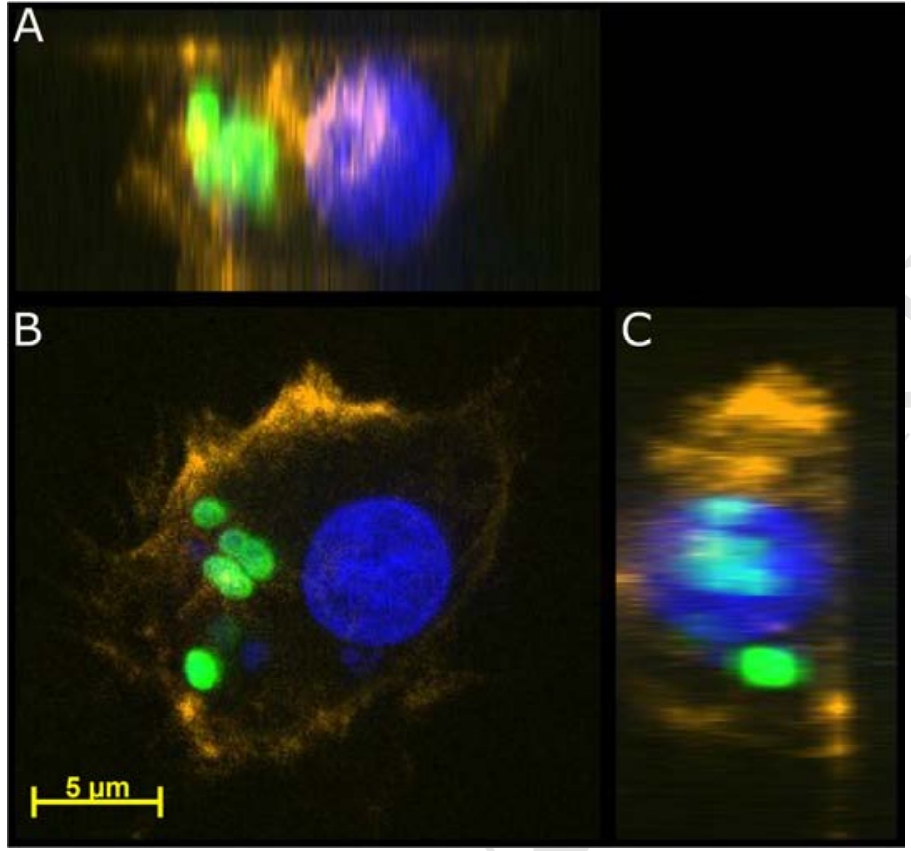

Fig. 5: 3-dimensional fluorescence microscopy (x60) pictures of a haemocyte (cytoskeleton in orange and nucleus in blue) which has phagocyted GFP-labelled $V$. harveyi (green). The central picture (B) shows a reconstruction of 14 stacked fluorescence images. The flanking pictures show cross-sections compiled along the $(\mathrm{A}) \mathrm{z}$-axis and $(\mathrm{C}) \mathrm{x}$-axis.

\subsubsection{Effect of the V. harveyi ECPs on the capacities of abalone to phagocyte this bacteria}

Haemocytes of abalones from each population were exposed to 0,15 and $30 \mu \mathrm{g} \cdot \mathrm{ml}^{-1}$ of ECPs obtained from the ORM4 strain of V. harveyi. Phagocytosis of GFP-labelled V. harveyi under exposure to ECPs was quantified two months after the successive infections experiment (Fig. 6). A nested ANOVA showed no significant differences between the Saint-Malo and Molène populations, but the factor ECPs exhibited a significant $p$-value $<0.001$. Thus, pairwise comparisons of Is-means were performed within each population in order to evaluate their responses to ECPs treatments. A concentration of $30 \mu \mathrm{g} \cdot \mathrm{ml}^{-1}$ ECPs showed a significant negative effect on the phagocytosis index of uninfected individuals, with an inhibition of phagocytosis of $19 \%$ for abalone from Molène and $22.8 \%$ for Saint-Malo. Abalones from Saint-Malo having survived the successive infections showed no significant difference in phagocytosis when exposed to 0,15 and $30 \mu \mathrm{g} \cdot \mathrm{ml}^{-1}$ of ECPs. 


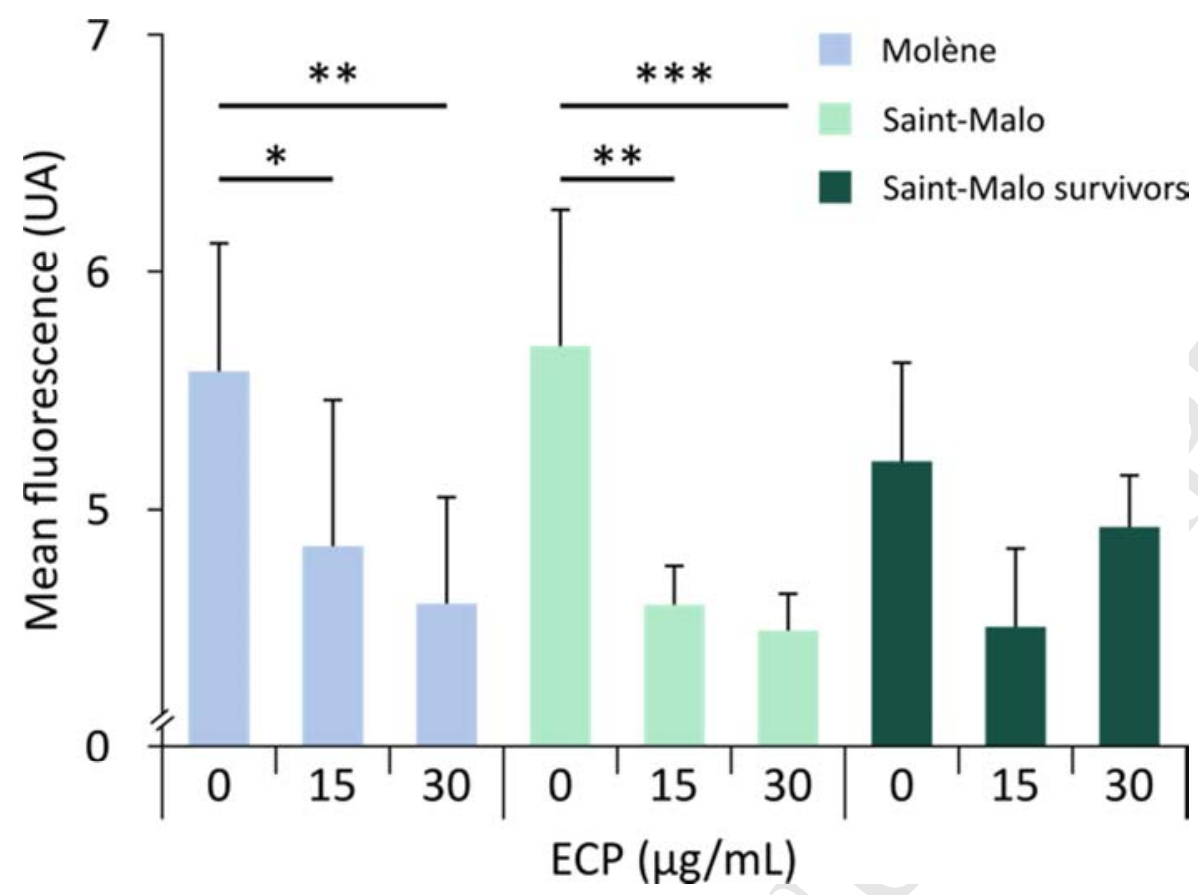

Fig. 6: Impact of two concentrations of extracellular products of $V$. harveyi $(15 \mu \mathrm{g} / \mathrm{mL}$ and 30 $\mu \mathrm{g} / \mathrm{mL}$ ) on phagocytosis of GFP-labelled bacteria. Values are the means of green fluorescence emitted by haemocytes. * indicates values that are significantly different from condition without ECPs for a pairwise comparison of the least-squares means $\left({ }^{*} \mathrm{P}<0.05,{ }^{*} \mathrm{P}<0.01,{ }^{* * *} \mathrm{P}\right.$ $<0.001)$.

3.5.3 Ability of $V$. harveyi to grow in acellular fraction of abalones hemolymph the necessary volume of serum, hemolymph of five individuals was pooled for each population. The two bacterial strains tested began their growth at approximately 2-3 hours earlier than in LBS, the positive control. Growth rate was faster in the pathogenic strain (ORM4) relative to the non-pathogenic (LMG7890). Moreover, the ability of $V$. harveyi to grow in abalone serum was lower in Saint-Malo ( $86 \%$ of the maximum growth rate observed in LBS for uninfected abalone and $92 \%$ for survivors), while the growth rate in the serum of abalone from Molène was nearly the same as in the LBS positive control (101\% of the rate observed in LBS). 

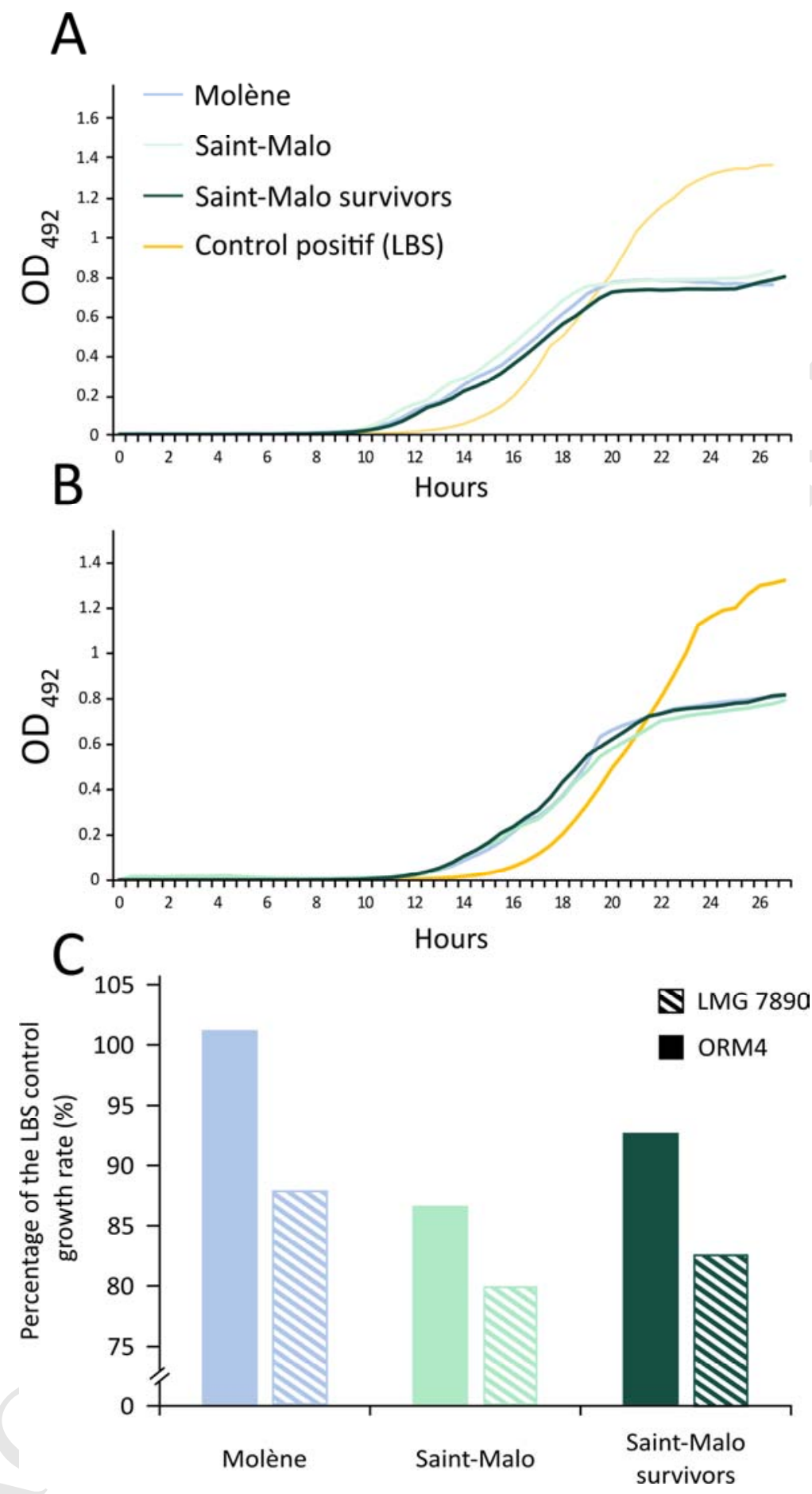

Fig. 7: Growth curves of the (A) non-virulent strain LMG7890 and (B) the virulent strain ORM4 in the serum of abalones. The growth of the bacteria in LBS was used as a positive control. (C) Growth rate of the LMH7890 and ORM4 strains in abalone serum are expressed as a percentage of the maximum growth rate in the LBS control. 
can evolve different susceptibilities against a particular pathogen. Based on this hypothesis, two populations of

364

365

366

367

368

369

370

371

372

373

374

375

376
$H$. tuberculata were chosen to examine how response to infection to $V$. harveyi could vary in abalone of different origins. In Saint-Malo, where the average sea water temperatures exceed $17^{\circ} \mathrm{C}$ during the summer spawning period, conditions are favorable for disease development and indeed, this population has been frequently impacted by disease [10]. On the other hand, mortality has never been reported in Molène and the surrounding region, where temperatures of $17^{\circ} \mathrm{C}$ are rarely observed[9]. Successive infections conducted with abalones from each of these two natural populations showed marked differences in survival. Following 24 days after a first exposure to $V$. harveyi, a survival rate of $51 \%$ was observed for abalone from Molène and $95 \%$ for abalone from Saint-Malo (Fig. 1). Interestingly, the survival rate for Saint-Malo was not statistically different from that of uninfected controls. Our experimental infections confirm the hypothesis that abalone from a site that has experienced recurrent mortality (Saint-Malo) shows improved survival following infection with $V$. harveyi. According to Coustau and Théron (2004), resistance is defined as a relative term which indicates that a group exhibits a significantly better ability to prevent infection by a specific pathogen. Thus, all subsequent analyses were performed to identify mechanisms which could explain the resistance to the disease observed in abalone from Saint-Malo.

Differences in survival of $H$. tuberculata following successive infection with $V$. harveyi $\left(10^{6}\right.$ bacteria $/ \mathrm{mL}$; $19^{\circ} \mathrm{C}$ ) has been previously observed in farmed abalones [17]. Survival rate improved from $36 \%$ after a first infection to $56 \%$ following a second exposure, revealing different levels of resistance to the disease within the farmed population and a better ability to resist a second infection. While reduced mortality in this experiment may have been due to immune priming, the enhanced resistance observed at the second exposure could also be explained as an elimination of susceptible phenotypes following the first infection. In order to isolate a priming effect, improved response to the disease needs to be observed in conditions where potentially susceptible phenotypes are not eliminated at a first infection. Therefore, in the present experiment, mild infection conditions in term of both temperature $\left(18^{\circ} \mathrm{C}\right)$ and bacterial concentration $\left(10^{4}\right.$ bacteria/mL $)$ were used to avoid mortality after a first exposure to $V$. harveyi, which was the case for the Saint-Malo population. Despite these infection conditions, survival was low in the susceptible population of Molène. Thus, these infection conditions allowed on one hand, to discriminate the two populations in term of resistance, and on the 
390

391

392

393

394

395

396

397

398

399

400

401

402

403

404

405

406

407

408

409

410

411

412

413

414

415

416

417

418

other hand, to discern which parameters allowed improved resistance to the disease in abalone from Saint-

Malo.

After the first infection with $V$. harveyi, individuals from both Saint-Malo and Molène suffered an important drop in phagocytosis ( $40 \%$ compared to the control) after the first day of exposure, followed by a recovery of this activity by the third day, showing a similar response between the two populations in cellular immunity during the first infection (Fig. 3). The reduction in phagocytosis index could be explained by the saturation of a high proportion of haemocytes following active phagocytosis of $V$. harveyi in the early stages of exposure, resulting in less efficient bead engulfment by 24 hours post-infection. Alternatively, the observed reduction in phagocytosis could be interpreted as an inhibition of phagocytosis. Previous studies have shown that the ORM4 strain can perturb the MAPK signaling pathway by inhibiting phosphorylation of the p38 MAPK, leading to inhibition of phagocytosis compared to the non-pathogenic strain of $V$. harveyi (LM7890)[16]. Moreover, a significant decrease in phagocytosis index 24 hours after exposure to $V$. harveyi is linked with a downregulation of clathrin, a protein involved in endocytosis [15]. Therefore, the lower phagocytosis index observed is likely due to an inhibition of phagocytosis induced by the pathogen.

Interestingly, no significant decrease in phagocytosis was observed 1 day after the second exposure for abalones from Saint-Malo (Fig. 3A). The response of this population to the second infection can be interpreted as an immune priming effect. The survival rates observed in the control and infected conditions in Saint-Malo were similar, supporting the interpretation that the improved response to an infection can be due to a priming effect rather than an elimination of susceptible phenotypes. For the Molène population, low survival rates following the first infection preclude such interpretation.

Immune priming allows invertebrates to show improved survival to a pathogen following a first infection. This mechanism is now known in several insect species [30-32] and the freshwater snail Biomphalaria glabrata $[20,33]$. In the marine realm, immune priming was first examined in copepods [34]. More recently, examples among a few marine molluscs have also been documented: Chlamys farreri [35], Mytilus galloprovincialis [36] and Crassostrea gigas [37]. In the gastropod Biomphalaria glabrata, a species phylogenetically close to $H$. tuberculata, a first exposure to the trematode Schistosoma mansoni conferred an immune priming effect which led to complete protection, such that a secondary infection exhibited animals with a parasite prevalence of $0 \%$ for primed individuals compared to $100 \%$ for unprimed [20]. In the Pacific oyster C. gigas, a more acute and rapid immune response in term of phagocytosis and hematopoiesis was 
observed after being primed with heat-killed Vibrio splendidus 7 days before the infection [35]. Since phagocytosis is usually the first response of the host against the pathogen, inhibition of this mechanism is a widespread strategy among pathogens to persist inside the host tissues [38]. Early phagocytosis response can then be crucial for the resistance of animals against infection and septicemia. In the case of $H$. tuberculata, the first exposure can act as an immune treatment that prevents future phagocytosis inhibition in abalone, thereby improving the early response to a subsequent exposure. A priming effect could allow the abalone immune system to be stimulated in the field at the beginning of the mortality season, thus enhancing protection for the rest of the critical period.

Because of the importance of the phagocytic response, and its implication in priming effect, this immune mechanism has been further examined. During the experimental infections, host phagocytosis was quantified using fluorescent beads. This commonly used approach [16] shows the activity of haemocytes rather than the actual ability to phagocytose a specific bacterium cell. While actual internalization of $V$. harveyi cells has previously been shown in primary cultured cells of farmed abalone haemolymph and gills [26], 3D fluorescent microscopy was used to confirm that this was the case in the freshly collected haemolymph from abalone from both Saint-Malo and Molène. Fluorescent microscopy shows that GFP-labelled bacterial cells are clearly observed inside the haemocytes, providing unquestionable evidence of internalization of $V$. harveyi by the haemocytes of $H$. tuberculata (Fig. 5) and confirming that subsequent flow cytometry measurements made with GFP-labelled V. harveyi quantifies actual phagocytosis. Phagocytosis of GFP-labelled bacteria performed two months after the infection experiment on uninfected individuals exhibited similar responses between the two populations. Abalones from Saint-Malo and Molène showed the same phagocytosis capacity and the same response to the ECPs. Indeed, the two populations suffer a phagocytosis inhibition of about $20 \%$ when exposed to $30 \mu \mathrm{g} \cdot \mathrm{ml}^{-1}$ of ECPs relative to the to the $0 \mu \mathrm{g} \cdot \mathrm{ml}^{-1}$ controls (Fig. 6). However, for the abalone from Saint-Malo surviving the successive infections, no statistical difference was observed between phagocytosis index exposed to concentrations of $0 \mu \mathrm{g}, 15 \mu \mathrm{g} \cdot \mathrm{ml}^{-1}$ and $30 \mu \mathrm{g} \cdot \mathrm{ml}^{-1}$ of ECPs, suggesting a potential long-term priming effect against the inhibition of phagocytosis induced by ECPs. This result indicates that the protection against phagocytosis inhibition induced by the first exposure has persisted for over two months.

Our results are the first to indicate the existence of immune priming in abalones, however, the present study does not differentiate between the two possible types of priming. Immune priming in invertebrates occurs either as a sustained response of immune mechanisms which prevents a subsequent attack, or via a 
specific response which allows recognition of the pathogen thus inducing a more intensive and rapid immune response [20]. Future work addressing whether sustained response or specificity of response is present in abalone could further our understanding of how immune priming acts in this species. For example, the injection of heat-killed bacteria could address whether immune priming is a specific response in $H$. tuberculata, as performed with the Pacific oyster [37]. Enhanced phagocytosis was observed only in oysters injected with heatkilled $V$. splendidus, but not with 4 other species of bacteria, suggesting specific recognition of this pathogen. The injection of heat-killed bacteria would also allow the induction of a more intensive immune effect by delivering higher doses of the pathogen. The infection performed in the present study was weak to avoid mortality, possibly leading to a partial or diminished immune priming response.

Sustained immune response is another possible mechanism of immune priming. The pathogenic strain of $V$. harveyi ORM4 is able to avoid the bactericidal response of abalone through an inhibition of the activity of the $\mathrm{p} 38$ MAPK, a MAP kinase which is thought to trigger a number of immune responses such as phagocytosis or the secretion of reactive oxygen species [16]. This kind of virulence has also been shown in other marine models. For example, the secretion of a metalloprotease by Vibrio aestuarianus, a pathogen of the Pacific oyster C. gigas, inhibits, among other immune parameters, phagocytosis [39]. Proteases secreted by the pathogen are a common mechanisms for the inhibition of phagocytosis, but can be counter-acted by protease inhibitors produced by the host [40]. In the disk abalone Haliotis discus discus, three types of clade B serine protease inhibitors are expressed in haemocytes following injection of $V$. parahaemolyticus or of LPS [41]. Sustained synthesis of protease inhibitors by $H$. tuberculata may therefore be a possible explanation of the long-term protection against phagocytosis inhibition. Future work quantifying protease inhibitors following successive infections with $V$. harveyi could confirm this hypothesis.

Humoral effectors may also contribute to the resistance of the Saint-Malo abalone to $V$. harveyi infection. Marine invertebrates possess a large set of antimicrobial peptides that can counteract bacterial growth [42]. Hemocyanin can also have strong antimicrobial activity [43], while other factors can limit bacterial growth by sequestering or limiting the availability of nutrients such as iron [44]. In the European abalone, the onset of growth of the two bacterial strains occurred 2-3 hours earlier in the serum of abalone than the LBS control, irrespective of the population, showing potential activators of bacterial growth may be present in the abalone serum. Moreover, bacterial growth rate was greater for the virulent strain of $V$. harveyi (ORM4) compared to the non-virulent strain LMG 7890 (Fig. 7). However, maximum growth rate of the virulent strain 
477

478

ORM4 was lower in the haemolymph of Saint-Malo compared to Molène, indicating that the serum of abalone from Saint-Malo is less favorable for ORM4 growth. Therefore, resistance to $V$. harveyi in abalone from SaintMalo may in part be explained by the ability to slow down bacterial growth within the serum. Host fluids can have significant effects in growth and gene expression of bacteria $[45,46]$. For example, the pedal mucus of the small abalone Haliotis diversicolor has been showed to induce the formation of a biofilm by Vibrio alginolyticus and to enhance the density of bacteria [46]. In the present work, bacterial growth in the serum was measured two months after the successive infections; it is possible that different responses may be observed during infection with $V$. harveyi.

The most striking differences between the resistant and susceptible populations were observed in the detection of $V$. harveyi in the haemolymph and the gills of abalone. In the haemolymph, $V$. harveyi was detected in only 5 individuals, all from the Molène population (Fig. 4A). Despite the low survival rate in abalone from Molène, the small number of individuals positive for $V$. harveyi can be explained by the rapid growth rate of $V$. harveyi in abalone serum ( 10 hours, see Fig 7$)$, rendering the time frame to detect the bacteria in hemolymph (between the beginning of exponential phase and septicemia) very short. It is nevertheless interesting to note that all individuals for which $V$. harveyi was detected were from Molène, suggesting that $V$. harveyi is better able to penetrate the haemolymph of abalone from this population. The results of THC support this interpretation. Although no differences in THC were observed between infected abalones and uninfected controls in the Saint-Malo population, abalone from Molène showed a significant increase of the number of circulating haemocytes after 24 hours of exposure to $V$. harveyi (Fig. 2). This likely denotes an inflammatory response by a recruitment of haemocytes in the hemocoel suggesting greater presence of $V$. harveyi in this compartment in abalone from Molène.

Detection of $V$. harveyi in the gills was significantly greater in abalone from Molène compared to SaintMalo (Fig. 4B), and a binomial regression showed that the detection of $V$. harveyi on the gills was correlated with an increase of THC and a decrease of phagocytosis index (Table. 1). These findings indicate that even if the bacterium is not detected in the haemolymph, its presence in the gills already induces an immune response. The portal of entry of $V$. harveyi is the gills of abalones [47], where previous work has shown that bacterial density can be 5 -fold greater in the gills compared to other tissues 6 hours after exposure. The small number of individuals which were positive for $V$. harveyi in the gills among abalone from Saint-Malo suggests that an important part of the resistance of this population may depend on the ability to prevent the settlement and 
506

507

508

509

510

511

512

513

514

515

516

517

518

519

520

521

522

523

524

525

526

527

528

529

530

531

532

533

534 penetration of bacteria in the gills. The ability to adhere to the portal of entry of the host can be essential for the virulence of a bacterium. This is the case of Flavobacterium colunmare and Yersinia ruckeri, for which all known virulent strains are able to adhere to the gills of their respective hosts, whereas non-virulent strains cannot $[48,49]$. Preventing settlement of bacteria on the gills may be an important defense mechanism against disease. Other strategies can also be used to counteract the settlement of bacteria on the gills of marine invertebrates, such as the localized production of lysozyme or antimicrobial peptides. In the penaid shrimp Marsupenaeus japonicas, lysozyme expression and antimicrobial activity are elevated in the gills [50]. Moreover, an antimicrobial peptide expressed only in gills has been discovered in the abalone Haliotis discus [51]. Since the gills may be important in the resistance to $V$. harveyi infection, future work comparing potential antimicrobial or anti-adherent activity in the gills of abalone from the two populations may help to identify the mechanisms by which abalone from Saint-Malo have enhanced resistance against $V$. harveyi.

Surprisingly, no individuals were positive for $V$. harveyi in the gills 3 days after the first exposure in both populations. This is possibly due to the fact that bacterial concentrations fluctuate over the course of the experimental infection, as was quantified in similar experiments [22]. Thus, bacterial concentrations at this given time point may have fallen below the detection limit.

\section{Conclusions}

This study shows the differential resistance between the two populations of $H$. tuberculata against $V$. harveyi and the comparisons between these two populations identified a number of resistance effectors. Abalone haemolymph exhibited weak defenses against the bacteria, and are presumably insufficient to contain a septicemia, although phagocytosis and limitation of bacterium growth in the serum are two possible resistance mechanisms. On the other hand, the significant differences observed in detection of $V$. harveyi in the gills point towards an important implication of the gills in the resistance of the Saint-Malo population. Our results show the first evidence of immune priming in Haliotis tuberculata and the enhanced capacity of phagocytosis at the second infection demonstrate a potential importance of cellular response against $V$. harveyi. A synergistic interaction among effectors in the gills and haemolymph likely lead to disease resistance. Further work is needed to understand precisely how the population of Saint-Malo resists infection and to find the gills effectors that counteract the settlement of $V$. harveyi in abalone gills. 
535

536

537

538

539

540

541

542

543

544

545

546

547

548

549

550

551

552

553

554

555

556

557

558

559

560

561

562

563

\section{Acknowledgments}

This work was supported by the "Laboratoire d'Excellence" LabexMER (ANR-10-LABX-19) and co-funded by a grant from the French government under the program "Investissements d'Avenir". The authors are grateful to RIERA Fabien; RICHARD Gaelle; HARNEY Ewan; LAISNEY Naïda; PETINAY Stephanie for their help in sampling during the infections experiment, and BIDAULT Adeline her assistance and suggestions for qPCR analyses. Finally, authors are also grateful to all the SMEL team for their help and their warm welcome within their structure.

\section{References}

[1] S. Altizer, D. Harvell, E. Friedle, Rapid evolutionary dynamics and disease threats to biodiversity, Trends Ecol. Evol. 18 (2003) 589-596. doi:10.1016/j.tree.2003.08.013.

[2] L. Wilfert, F.M. Jiggins, The dynamics of reciprocal selective sweeps of host resistance and a parasite counter-adaptation in drosophila, Biol. Lett. 6 (2010) 666-8. doi:10.1098/rsbl.2010.0329.

[3] C.D. Harvell, C. E.Mitchell, R.W. Jessica, A. Sonia, P.D. Andrew, R. S.Ostfeld, et al., Climate warming and disease risks for terrestrial and marine biota, Science (80-. ). 296 (2002) 2158-2162. doi:10.1126/science.1063699.

[4] W. Cheng, I.S. Hsiao, C.-H. Hsu, J.C. Chen, Change in water temperature on the immune response of Taiwan abalone Haliotis diversicolor supertexta and its susceptibility to Vibrio parahaemolyticus, Dis. Aquat. Organ. 60 (2004) 157-164. doi:10.1016/j.fsi.2004.03.007.

[5] L. Vezzulli, I. Brettar, E. Pezzati, P.C. Reid, R.R. Colwell, M.G. Höfle, et al., Long-term effects of ocean warming on the prokaryotic community: evidence from the vibrios, ISME J. 6 (2012) 21-30. doi:10.1038/ismej.2011.89.

[6] K.K. Lee, P.C. Liu, Y.C. Chen, C.Y. Huang, The implication of ambient temperature with the outbreak of vibriosis in cultured small abalone Haliotis diversicolor supertexta Lischke, J. Therm. Biol. 26 (2001) 585-587. doi:10.1016/S0306-4565(01)00004-3.

[7] M. Monari, V. Matozzo, J. Foschi, O. Cattani, G.P. Serrazanetti, M.G. Marin, Effects of high temperatures on functional responses of haemocytes in the clam Chamelea gallina, Fish Shellfish Immunol. 22 (2007) 98-114. doi:10.1016/j.fsi.2006.03.016.

[8] J.L. Nicolas, O. Basuyaux, J. Mazurié, A. Thébault, Vibrio carchariae, a pathogen of the abalone Haliotis 
tuberculata, Dis. Aquat. Organ. 50 (2002) 35-43. doi:10.3354/dao050035.

565 [9] A. Thébault, Bilan 1998 du Réseau REPAMO, 1998.

566 [10] S. Huchette, J. Clavier, status of the ormer (haliotis tuberculata L.) industry in europe, J. Shellfish Res. 23 (2004) $951-955$.

568

[11] M.-A. Travers, O. Basuyaux, N. Le Goïc, S. Huchette, J.-L. Nicolas, M. Koken, et al., Influence of temperature and spawning effort on Haliotis tuberculata mortalities caused by Vibrio harveyi : an example of emerging vibriosis linked to global warming, Glob. Chang. Biol. 15 (2009) 1365-1376. doi:10.1111/j.1365-2486.2008.01764.x.

M.-A. Travers, N. Le Goïc, S. Huchette, M. Koken, C. Paillard, Summer immune depression associated with increased susceptibility of the European abalone, Haliotis tuberculata to Vibrio harveyi infection, Fish Shellfish Immunol. 25 (2008) 800-808. doi:10.1016/j.fsi.2008.08.003.

[13] M. Cardinaud, C. Offret, S. Huchette, D. Moraga, C. Paillard, The impacts of handling and air exposure on immune parameters, gene expression, and susceptibility to vibriosis of European abalone Haliotis tuberculata, Fish Shellfish Immunol. 36 (2014) 1-8. doi:10.1016/j.fsi.2013.09.034. M. Collins, R. Knutti, J. Arblaster, J.-L. Dufresne, T. Fichefet, P. Friedlingstein, et al., Long-term Climate

M. Cardinaud, N.M. Dheilly, S. Huchette, D. Moraga, C. Paillard, The early stages of the immune response of the European abalone Haliotis tuberculata to a Vibrio harveyi infection, Dev. Comp. Immunol. 51 (2015) 287-297. doi:10.1016/j.dci.2015.02.019. Vibrio harveyi, J. Invertebr. Pathol. 105 (2010) 289-297. doi:10.1016/j.jip.2010.08.001.

M.-A. Travers, R. Le Bouffant, C.S. Friedman, F. Buzin, B. Cougard, S. Huchette, et al., Pathogenic vibrio harveyi, in contrast to non-pathogenic strains, intervenes with the p38 MAPK pathway to avoid an abalone haemocyte immune response, J. Cell. Biochem. 106 (2009) 152-160. doi:10.1002/jcb.21990. 
593

594

595

596

597

598

599

600

601

602

603

604

605

606

607

608

609

610

611

612

613

614

615

616

617

618

619

620

621

doi:10.3389/fmicb.2014.00078.

[19] J. Kurtz, Specific memory within innate immune systems, Trends Immunol. 26 (2005) 186-192. doi:10.1016/j.it.2005.02.001.

[20] J. Portela, D. Duval, A. Rognon, R. Galinier, J. Boissier, C. Coustau, et al., Evidence for specific genotypedependent immune priming in the lophotrochozoan Biomphalaria glabrata snail., J. Innate Immun. 5 (2013) 261-76. doi:10.1159/000345909.

[21] Y. Moret, Trans-generational immune priming": specific enhancement of the antimicrobial immune response in the mealworm beetle, Tenebrio molitor., Proc. Biol. Sci. 273 (2006) 1399-405. doi:10.1098/rspb.2006.3465.

[22] M.-A. Travers, A. Barbou, N. Le Goïc, S. Huchette, C. Paillard, M. Koken, Construction of a stable GFPtagged Vibrio harveyi strain for bacterial dynamics analysis of abalone infection., FEMS Microbiol. Lett. 289 (2008) 34-40. doi:10.1111/j.1574-6968.2008.01367.x.

[23] D. Schikorski, T. Renault, C. Paillard, D. Tourbiez, D. Saulnier, Development of TaqMan real-time PCR assays for monitoring Vibrio harveyi infection and a plasmid harbored by virulent strains in European abalone Haliotis tuberculata aquaculture, 395 (2013) 106-112. doi:10.1016/j.aquaculture.2013.02.005.

[24] P. V Liu, Survey of hemolysin production among species of pseudomonas, Infect. Immun. (1957) 718727.

[25] L.S. Ramagli, 2-D Proteome Analysis Protocols, in: A.J. Link (Ed.), Humana Press, Totowa, NJ, 1999: pp. 99-103. doi:10.1385/1-59259-584-7:99.

[26] D. Pichon, B. Cudennec, S. Huchette, Characterization of abalone Haliotis tuberculata-Vibrio harveyi interactions in gill primary cultures, Cytotechnology. (2013) 759-772. doi:10.1007/s10616-013-9583-1.

[27] T.M. Therneau, A Package for Survival Analysis in S, (2015). http://cran.r-project.org/package=survival.

[28] R Core Team, R: A Language and Environment for Statistical Computing, (2015). https://www.rproject.org/.

[29] C. Coustau, A. Théron, Resistant or resisting: seeking consensus terminology, Trends Parasitol. 20 (2004) 208-209. doi:10.1016/j.pt.2004.02.006.

[30] G. Wu, M. Li, Y. Liu, Y. Ding, Y. Yi, The specificity of immune priming in silkworm, Bombyx mori, is mediated by the phagocytic ability of granular cells, J. Insect Physiol. 81 (2015) 60-68. doi:10.1016/j.jinsphys.2015.07.004. 
622

623

624

625

626

627

628

629

630

631

632

633

634

635

636

637

638

639

640

641

642

643

644

645

646

647

648

649

650

[31] G. Wu, Z. Zhao, C. Liu, L. Qiu, Priming Galleria mellonella (Lepidoptera: Pyralidae) Larvae With HeatKilled Bacterial Cells Induced an Enhanced Immune Protection Against Photorhabdus luminescens TT01 and the Role of Innate Immunity in the Process, (2004) 2-5.

[32] Z. Zhao, G. Wu, J. Wang, C. Liu, L. Qiu, Next-generation sequencing-based transcriptome analysis of Helicoverpa armigera larvae immune-primed with Photorhabdus luminescens TT01, PLoS One. 8 (2013) e80146. doi:10.1371/journal.pone.0080146.

[33] S. Pinaud, J. Portela, D. Duval, F.C. Nowacki, M.A. Olive, J.F. Allienne, et al., A Shift from Cellular to Humoral Responses Contributes to Innate Immune Memory in the Vector Snail Biomphalaria glabrata, PLoS Pathog. 12 (2016) 1-18. doi:10.1371/journal.ppat.1005361.

[34] J. Kurtz, K. Franz, Evidence for memory in invertebrate immunity., Nature. 425 (2003) 37-38. doi:10.1038/425037a.

[35] M. Cong, L. Song, L. Wang, J. Zhao, L. Qiu, L. Li, et al., The enhanced immune protection of Zhikong scallop Chlamys farreri on the secondary encounter with Listonella anguillarum, Comp. Biochem. Physiol. - B Biochem. Mol. Biol. 151 (2008) 191-196. doi:10.1016/j.cbpb.2008.06.014.

[36] C. Ciacci, B. Citterio, M. Betti, B. Canonico, P. Roch, L. Canesi, Functional differential immune responses of Mytilus galloprovincialis to bacterial challenge, Comp. Biochem. Physiol. - B Biochem. Mol. Biol. 153 (2009) 365-371. doi:10.1016/j.cbpb.2009.04.007.

[37] T. Zhang, L. Qiu, Z. Sun, L. Wang, Z. Zhou, R. Liu, et al., The specifically enhanced cellular immune responses in Pacific oyster (Crassostrea gigas) against secondary challenge with Vibrio splendidus, Dev. Comp. Immunol. 45 (2014) 141-150. doi:10.1016/j.dci.2014.02.015.

[38] B. Allam, D. Raftos, Immune responses to infectious diseases in bivalves, J. Invertebr. Pathol. 131 (2015) 121-136. doi:10.1016/j.jip.2015.05.005.

[39] Y. Labreuche, F. Le Roux, J. Henry, C. Zatylny, A. Huvet, C. Lambert, et al., Vibrio aestuarianus zinc metalloprotease causes lethality in the Pacific oyster Crassostrea gigas and impairs the host cellular immune defenses, Fish Shellfish Immunol. 29 (2010) 753-758. doi:10.1016/j.fsi.2010.07.007.

[40] P.B. Armstrong, Proteases and protease inhibitors: a balance of activities in host-pathogen interaction, Immunobiology. 211 (2006) 263-281. doi:10.1016/j.imbio.2006.01.002.

[41] S.D.N.K. Bathige, N. Umasuthan, G.I. Godahewa, I. Whang, C. Kim, H.C. Park, et al., Three novel clade B serine protease inhibitors from disk abalone, Haliotis discus discus: Molecular perspectives and 
651

652

653

654

655

656

657

658

659

660

661

662

663

664

665

666

667

668

669

670

671

672

673

674

675

676

677

678 responses to immune challenges and tissue injury, Fish Shellfish Immunol. 45 (2015) 334-341. doi:10.1016/j.fsi.2015.04.020.

[42] J. Tincu, S. Taylor, Antimicrobial peptides from marine invertebrates, Antimicrob. Agents Chemother. 48 (2004) 3645-3654. doi:10.1128/AAC.48.10.3645.

[43] P. Dolashka, Moshtanska, A. Dolashki, J. Van Beeumen, M. Floetenmeyerd, L. Velkova, et al., Antimicrobial Activity of Molluscan Hemocyanins from Helix and Rapana Snails, Curr. Pharm. Biotechnol. 16 (2015) 1-1. doi:10.2174/1389201016666150907113435.

[44] C.P. Doherty, Host-pathogen interactions: the role of iron., J. Nutr. 137 (2007) 1341-1344.

[45] A.M. Staroscik, D.R. Nelson, The influence of salmon surface mucus on the growth of Flavobacterium columnare, J. Fish Dis. 31 (2008) 59-69. doi:10.1111/j.1365-2761.2007.00867.x.

[46] F. Guo, Z. bin Huang, M. qin Huang, J. Zhao, C. huan Ke, Effects of small abalone, Haliotis diversicolor, pedal mucus on bacterial growth, attachment, biofilm formation and community structure, Aquaculture. 293 (2009) 35-41. doi:10.1016/j.aquaculture.2009.03.033.

[47] M. Cardinaud, A. Barbou, C. Capitaine, A. Bidault, A.M. Dujon, D. Moraga, et al., Vibrio harveyi adheres to and penetrates tissues of the European abalone Haliotis tuberculata within the first hours of contact, Appl. Environ. Microbiol. 80 (2014) 6328-6333. doi:10.1128/AEM.01036-14.

[48] E. Tobback, A. Decostere, K. Hermans, W. Van den Broeck, F. Haesebrouck, K. Chiers, In vitro markers for virulence in Yersinia ruckeri, J. Fish Dis. 33 (2010) 197-209. doi:10.1111/j.1365-2761.2009.01106.x.

[49] O. Olivares-Fuster, S.A. Bullard, A. McElwain, M.J. Llosa, C.R. Arias, Adhesion dynamics of Flavobacterium columnare to channel catfish Ictalurus punctatus and zebrafish Danio rerio after immersion challenge, Dis. Aquat. Organ. 96 (2011) 221-227. doi:10.3354/dao02371.

[50] A. Kaizu, F.F. Fagutao, H. Kondo, T. Aoki, I. Hirono, Functional analysis of C-type lysozyme in penaeid shrimp, J. Biol. Chem. 286 (2011) 44344-44349. doi:10.1074/jbc.M111.292672.

[51] J.-K. Seo, H.-J. Go, C.-H. Kim, B.-H. Nam, N.G. Park, Antimicrobial peptide, hdMolluscidin, purified from the gill of the abalone, Haliotis discus, Fish Shellfish Immunol. 52 (2016) 289-297.

doi:10.1016/j.fsi.2016.03.150. 
679

680

681

682

683

684

685

686

687

688

689

690

691

692

693

694

695

696

697

698

699

700

701

702

703

\section{Captions}

Figure 1: Kaplan-Meier survival rate following the first exposure of the two populations to $10^{4}$ bacteria/mL during 24 hours at $18^{\circ} \mathrm{C}$

Figure 2: Total haemocytes count (THC) during the two exposures of (A) Saint-Malo and (B) Molène. Red dots indicate the exposures. ND indicates that no data is available.* indicates values that are significantly different from the control for a pairwise comparison of the least-squares means $(p<$ $0.05)$.

Figure 3: Phagocytosis index based on micro-beads engulfment (percentage of haemocytes containing three or more fluorescent beads relative to total haemocytes) during two successive infections of abalone from (A) Saint-Malo and (B) Molène. Red dots indicate the timing of bacterial exposure. ND indicates that no data is available.* indicates values that are significantly different from the control for a pairwise comparison of the least-squares means $(p<0.05)$.

Figure 4: Percentage of positive individuals for V.harveyi $(n=9)$ in $(A)$ haemolymph and (B) gills obtained by qPCR using specific primers and a TaqMan probe. The number 0 indicates that no individuals were found as positive at a given population and time point. Red dots indicate the timing of bacterial exposure. ND indicates that no data is available.

Figure 5: 3-dimensional fluorescence microscopy $(x 60)$ pictures of a haemocyte (cytoskeleton in orange and nucleus in blue) which has phagocyted GFP-labelled V. harveyi (green). The central picture (B) shows a reconstruction of 14 stacked fluorescence images. The flanking pictures show cross-sections compiled along the (A) z-axis and (C) x-axis.

Figure 6: Impact of two concentrations of extracellular products of $V$. harveyi $(15 \mu \mathrm{g} / \mathrm{mL}$ and 30 $\mu \mathrm{g} / \mathrm{mL}$ ) on phagocytosis of GFP-labelled bacteria. Values are the means of green fluorescence emitted by haemocytes. ${ }^{*}$ indicates values that are significantly different from condition without ECPs for a pairwise comparison of the least-squares means ( $\left.{ }^{*} P<0.05,{ }^{* * P}<0.01,{ }^{* * * P}<0.001\right)$. Figure 7: Growth curves of the (A) non-virulent strain LMG7890 and (B) the virulent strain ORM4 in 
704 the serum of abalones. The growth of the bacteria in LBS was used as a positive control. (C) Growth 705 rate of the LMH7890 and ORM4 strains in abalone serum are expressed as a percentage of the 706 maximum growth rate in the LBS control. 